\title{
Building a Cellular Networking Research Program
}

\author{
Li Erran Li \\ (Moderator) \\ Bell Labs \\ Alcatel-Lucent \\ erranlli@research.bell- \\ labs.com
}

\author{
Songwu Lu \\ Department of Computer \\ Science \\ University of California, Los \\ Angeles \\ slu@cs.ucla.edu
}

\author{
Chunyi Peng \\ Dept. of Computer Science \\ and Engineering \\ Ohio State University \\ chunyi@cse.ohio- \\ state.edu
}

\author{
Jacobus Van der Merwe \\ School of Computing \\ University of Utah \\ kobus@cs.utah.edu
}

\section{Categories and Subject Descriptors}

C. 2 [Computer System Organization]: Computer Communication Networks

\section{Keywords}

Cellular networks
Permission to make digital or hard copies of part or all of this work for personal or classroom use is granted without fee provided that copies are not made or distributed for profit or commercial advantage, and that copies bear this notice and the full citation on the first page. Copyrights for third-party components of this work must be honored. For all other uses, contact the owner/author(s). Copyright is held by the author/owner(s).

AllThingsCellular'14, August 22, 2014, Chicago, IL, USA.

ACM 978-1-4503-2990-3/14/08.

http://dx.doi.org/10.1145/2627585.2627593.
Dept. of Electrical and

Computer Engineering

Rice University

Izhong@rice.edu

\begin{abstract}
While innovations in mobile services and applications have been more limited. This is partially caused by the closed research community. This panel will discuss effective ways networking research programs in light of lar technologies such as SDN, NFV, new waveforms, M2M, millimeter waves, etc.

ABSTRACT
\end{abstract} . 